\title{
Responses of chlorophyll a content for conchocelis phase of alaskan porphyra (bangiales, rhodophyta) species to environmental factors
}

\author{
Rulong Lin ${ }^{1, *}$, Michael Steven Stekoll ${ }^{2}$ \\ ${ }^{1}$ Key Laboratory of Global Change and Marine-Atmospheric Chemistry, State OceanicAdministration, and Third Institute of \\ Oceanography, State Oceanic Administration, Xiamen 361005, China \\ ${ }^{2}$ Juneau Center, School of Fisheries and Ocean Science, University of Alaska, 11120 Glacier Highway, Juneau, AK99801, U.S.A
}

\section{Email address:}

linrulong@yahoo.com(R. Lin)

To cite this article:

Rulong Lin, Michael Steven Stekoll, Responses of Chlorophyll a Content for Conchocelis Phase of Alaskan Porphyra (Bangiales,Rhodophyta) Species to Environmental Factors. Advances in Bioscience and Bioengineering. Vol. 1, No. 1, 2013 , pp. $28-39$. doi: 10.11648/j.abb.20130101.14

\begin{abstract}
Investigations were performed on variations of photosynthetic pigment in conchocelis of Alaskan Porphyra species, $P$. abbottae $(\mathrm{Pa})$, P. pseudolanceolata $(\mathrm{Pe})$, P. pseudolinearis $(\mathrm{Pi})$ and $P$. torta $(\mathrm{Pt})$, in response to environmental variables. Conchocelis were cultured under varying conditions of irradiance $\left(0,10,40\right.$ and $160 \mu$ mol photons m $\left.{ }^{-2} \mathrm{~s}^{-1}\right)$, nutrient concentration $(0, \mathrm{f} / 4, \mathrm{f} / 2$ and $\mathrm{f})$ for up to 60 days (with temperature $11^{\circ} \mathrm{C}$ and salinity $30 \mathrm{ppt}$ ). Chlorophyll $a(\mathrm{Chl} a$ ) content was measured by spectrophotometry. Results indicated that Chl content varied with different culture conditions and species. Photosynthetic pigment was significantly affected by irradiance, nutrient concentration and culture duration, including some interactions of major factors for different species. Light had the most obvious influence on pigment content. For all four species and culture conditions tested, the higher $\mathrm{Chl} a$ content $(3.6-8.6 \mathrm{mg} / \mathrm{g} . \mathrm{dw})$ generally occurred at $0-10 \mu \mathrm{mol}$ photons $\mathrm{m}^{-2} \mathrm{~s}^{-1}$ than at higher irradiances $\left(\geq 40 \mu \mathrm{mol}\right.$ photons $\left.\mathrm{m}^{-2} \mathrm{~s}^{-1}\right)$ culture. For all culture conditions, Chl $a$ content in conchocelis culture with no nutrients added was the lowest. Although there was some difference in Chl $a$ content for cultures with $\mathrm{f} / 2$-f nutrient concentration, it was not statistically significant. ANOVA results showed that culture duration had influence on $\mathrm{Chl} a$ content of $\mathrm{Pa}$, Pe and Pi species. However, pooled data analysis indicated there was no obvious difference in Chl content for four species of 10-60day culture. There were significant differences in photosynthetic pigment content for different species. Pa and Pi produced much higher pigment content than the other two species responding to different environmental conditions. Maximal Chl. $a$ content $(8.6 \mathrm{mg} / \mathrm{g} . \mathrm{dw})$ for Pa occurred at $0 \mu$ mol photons $\mathrm{m}^{-2} \mathrm{~s}^{-1}, \mathrm{f} / 2$ nutrient concentration and 10 day culture duration. Pt contained the lowest pigment content for all culture conditions. Photosynthetic pigment remained relatively higher content under the complete darkness or the low irradiance continuously as long as 60 days for all tested species, which demonstrated the unique survival feature of Porphyra conchocelis. Variation patterns of pigment content, ecological significance and adaptation strategy to low or dark light conditions for microscopic conchocelis stage of Porphyra were discussed.
\end{abstract}

Keywords: Porphyra, Conchocelis, Photosynthetic Pigment, Chlorophyll A, Irradiance, Temperature, Nutrient, Environmental Factor, Alaska

\section{Introduction}

Among more than 440 species of marine algae in Alaskan waters, quite a few Porphyra have ecological significance and potential commercial value for successful utilization in mariculture $[1,2]$. Porphyra is ranked the highest valued nearshore fishery. The food product often known as "nori" from Porphyra, sold in the form of dried and roasted sheets, is worth $\$ 1.4$ billion per year and is one of the major aquaculture products produced in the world [3]. There is a growing worldwide market for this and other Porphyra products[4-9].

In the life cycle of Porphyra, two distinct phases are involved. One is the gametophyte, the macroscopic leafy thallus phase known as Porphyra. The other is the microscopic, filamentous sporophyte called the conchocelis stage, which generally lives inside shells in natural habitats 
[10-14]. Mariculture of all species of Porphyra requires artificial control of the life cycle to regulate the production of spores for seeding nets. The quality, quantity, and control of the conchocelis stage are important for successful Porphyra aquaculture [2, 15-16]. One potentially useful indicator of the quality of the conchocelis stage can be the photosynthetic pigment content [17-19]. Although there have been many studies dealing with the classification, morphology, life history, development, growth, desiccation tolerance and ecology regarding the gametophyte stage of Porphyra species from different geographic distributions [20-35], relatively few studies have investigated the physiology and biochemistry of the microscopic conchocelis stage[36, 37]. Chlorophyll $a$ is the most important light-harvesting pigments in the chloroplasts of marine red algae. In photosynthetic process of red algae, accessory pigments (including phycobilins and carotenoids) absorb the particular wavelengths of light and transfer the light energy to chlorophyll $a$, which is responsible for converting all the absorbed light energy into the chemical energy in ATP and NADPH that are used in the synthesis of organic compounds from the carbon dioxide [38]. Therefore, harvesting pigments play the important roles in the utilization and absorption of light energy and are crucial in determining physiological responses of the Porphyra microscopic stage to the environmental change. Environmental factors may exert profound influences on important physiological processes and on the biochemical composition of the conchocelis filaments. Environmental factors should be examined to investigate their influences on important physiological processes and the biochemical composition of the Porphyra conchocelis stage and to produce high quality and quantity of conchocelis. To date, we have little information about how environmental factors affect the pigment content of the conchocelis stage of Porphyra. Studies are needed on the basic information how environmental factors affect the pigment content of the Porphyra microscopic stage. We report here on responses of photosynthetic pigment contents of Alaskan Porphyra conchocelis to the variations of multiple environmental variables.

\section{Materials and Methods}

\subsection{Culture of Porphyra Conchocelis}

Unialgal cultures of each Porphyra species (Porphyra abbottae Krishnamurthy - strain PaSGS01, $P$. pseudolanceolata Krishnamurthy - strain PeJB03, $P$. pseudolinearis Ueda - strain PiSC14 and $P$. torta Krishnamurthy - strain PtCH13a) were obtained from carpospore release. Mature blades of the gametophyte stage of each species were collected from the field. Blades were washed and scrubbed with sterile seawater to remove surface contamination. The cleaned blades were placed in sterile seawater in petri dishes for carpospore release. After 24-36 hours the blades were removed and the dishes incubated in Provasoli's enriched seawater [39] under 16L:8D photoperiod at $11^{\circ} \mathrm{C}$. Conchocelis segments (around 110-250 $\mu \mathrm{m}$ ) of each species were placed in cell well plates (one piece per well) and incubated at $30 \mathrm{ppt}$ salinity and $11^{\circ} \mathrm{C}\left(100-120 \mu \mathrm{mol}\right.$ photons $\mathrm{m}^{-2} \mathrm{~s}^{-1}$ irradiance) for the culture of pure genotype conchocelis, which were used for culture of bulk conchocelis materials for experiments. PES enriched seawater culture medium was used for conchocelis stage. Conchocelis were incubated at $11^{\circ} \mathrm{C}$ and $25 \mu \mathrm{mol}$ photons $\mathrm{m}^{-2} \mathrm{~s}^{-1}$ irradiance with $\mathrm{f} / 2$ culture media.

\subsection{Experimental Methods}

Pigment experiments of conchocelis were conducted in the incubator which had been set at $11^{\circ} \mathrm{C}$ of temperature and illuminated with cool-white fluorescent lamps. Irradiance gradients were obtained by wrapping the culture containers with varying layers of white paper and determined using a Li-Cor Radiation Sensor (Li-190SB Quantum Sensor). The $\mathrm{pH}$ of the culture medium was adjusted to $7.8-8.0$ (the ambient $\mathrm{pH}$ of the seawater in the inside waters of SE Alaska) using $6 \mathrm{M} \mathrm{HCl}$ or $6 \mathrm{M} \mathrm{NaOH}$. The salinity of experimental seawater was set at 30ppt. Culture media were changed every 7 days. Long day (16L: 8D) photoperiods were used. Nutrients were added as an $\mathrm{f}$ culture medium concentration, which has a nitrogen concentration of $5.873 \mathrm{mmol}$. Therefore, nutrient levels of $0, \mathrm{f} / 4, \mathrm{f} / 2$ and $\mathrm{f}$ concentrations represented $0.02,1.468$, 2.936 and $5.873 \mathrm{mmol}$ of nitrogen concentration respectively (conchocelis at 0 nutrient concentration represented those incubated in natural seawater with a nitrogen concentration of $0.02 \mathrm{mmol}$, i.e., no $\mathrm{f}$ culture medium was added). In order to ensure sufficient inorganic carbon source available to the conchocelis, culture media were supplemented with $5 \mathrm{mM} \mathrm{NaHCO}_{3}$. For pigment experiments, different levels of three environmental factors were employed: nutrient levels of $0, \mathrm{f} / 4, \mathrm{f} / 2, \mathrm{f}$ concentration; irradiances of $0,10,40,160 \mu \mathrm{mol}$ photons $\mathrm{m}^{-2} \mathrm{~s}^{-1}$; culture duration of 10, 20, 30, 60 days.

\subsection{Procedure for Measurement and Analysis of Pigment Content}

Porphyra conchocelis were grown in $200 \mathrm{ml}$ flasks under the different culture conditions. After being incubated for $10,20,30,60$ days, conchocelis samples were rinsed with sterile seawater and ground at low temperature and low light. Chlorophyll $a$ content was measured and analyzed on the basis of its absorption peak value at the wavelength of maximum light absorption $(670 \mathrm{~nm})$ after the samples were ground and extracted by the organic solvent (acetone, 90\%) with one drop of saturated $\mathrm{MgCO}_{3}$ added and centrifuged at $14,000 \mathrm{~g}$ for 30 minutes. About 4-6 mg f.w. conchocelis was used for chlorophyll a measurements. Four replicates of conchocelis samples from each combination of culture conditions were used for the pigment measurement and one corresponding sample was used for measurement of the 
ratio of dry weight and fresh weight. Pigments were extracted at the low temperature and in the dark. Volume of the extracted pigment solution was set to $2 \mathrm{ml}$ for the pigment measurement. Specific extinction coefficient used to calculate pigment amount in the red algal pigment extracts was obtained from O'hEocha [40]. Pigment absorbencies were determined using a Gilford spectrophotometer 250 .

The following formula was used for the estimation of pigment content in conchocelis samples on the basis of the absorbancies of the pigment extracts at specified wavelengths and its corresponding specific extinction coefficient:
Chlorophyll $a\left(\mathrm{mg} \mathrm{g.dw}^{-1}\right)=\left(19.8 \mathrm{~A}_{670}\right) /$ sample amount (mg.dw)

\subsection{Statistical Analyses of the Experimental Data}

The factoral effects (including potential factor interactions) were analyzed by using a three-way model I ANOVA (pigment content as a function of light, nutrient, culture duration) and S-Plus 4.5 for windows [41]. The Newman-Keuls multiple comparison test [42] was performed to identify which tested factors were important in controlling pigment content of Porphyra. conchocelis.

Table 1. ANOVA table for chlorophyll a content of the conchocelis of four Porphyra species at combinations of nutrient concentration (Nc), irradiance (Light) and culture duration (day). At $0, f / 4, f / 2, f ; b 0,10,40,160 \mu$ mol photons $m^{-2} s^{-1} ;{ }^{c} 10,20,30,60$ days. (*P<0.05;**P<0.01)

\begin{tabular}{|c|c|c|c|c|}
\hline Source of variation & df & Sum of squares & Mean square & $\mathbf{F}$ \\
\hline \multicolumn{5}{|l|}{ P. abbottae } \\
\hline Nutrient $^{a}$ & 3 & 39.3185 & 13.1062 & $18.203 * *$ \\
\hline Light $^{b}$ & 3 & 832.2614 & 277.4205 & $385.302 * *$ \\
\hline Durationc $^{c}$ & 3 & 109.0687 & 36.3562 & $50.494 * *$ \\
\hline Nc $x$ Light & 9 & 36.9991 & 4.1110 & $5.710 * *$ \\
\hline Nc x Day & 9 & 22.0478 & 2.4498 & $3.402 * *$ \\
\hline Light x Day & 9 & 26.5725 & 2.9525 & $4.101 * *$ \\
\hline Nc x Light x Day & 27 & 21.1674 & 0.7840 & 1.089 \\
\hline Residuals & 192 & 138.2416 & 0.7200 & \\
\hline \multicolumn{5}{|l|}{ P. pseudolanceolata } \\
\hline Nutrient ${ }^{a}$ & 3 & 34.7435 & 11.5812 & $18.994 * *$ \\
\hline Light $^{b}$ & 3 & 42.5447 & 14.1816 & $23.258 * *$ \\
\hline Durationc $^{c}$ & 3 & 33.3750 & 11.1250 & $18.246^{* *}$ \\
\hline Nc $x$ Light & 9 & 6.0534 & 0.6726 & 1.103 \\
\hline Nc x Day & 9 & 4.0953 & 0.4550 & 0.746 \\
\hline Light x Day & 9 & 34.1028 & 3.7892 & $6.214 * *$ \\
\hline Nc x Light $x$ Day & 27 & 18.3748 & 0.6805 & 1.116 \\
\hline Residuals & 192 & 117.0698 & 0.6097 & \\
\hline \multicolumn{5}{|l|}{ P. pseudolinearis } \\
\hline Nutrient ${ }^{a}$ & 3 & 77.7924 & 25.9308 & $27.179 * *$ \\
\hline Light $^{b}$ & 3 & 318.3588 & 106.1196 & $111.227 * *$ \\
\hline Durationc $^{c}$ & 3 & 24.0444 & 8.0148 & $8.401 * *$ \\
\hline Nc $x$ Light & 9 & 50.9408 & 5.6601 & $5.932 * *$ \\
\hline Nc x Day & 9 & 33.4742 & 3.7194 & $3.898 * *$ \\
\hline Light x Day & 9 & 32.3669 & 3.5963 & $3.769 * *$ \\
\hline Nc x Light $x$ Day & 27 & 45.1706 & 1.6730 & $1.754 *$ \\
\hline Residuals & 192 & 183.1837 & 0.9541 & \\
\hline \multicolumn{5}{|l|}{ P. torta } \\
\hline Nutrient $^{a}$ & 3 & 9.5275 & 3.1758 & $5.805 * *$ \\
\hline Light $^{b}$ & 3 & 135.0219 & 45.0073 & $82.272 * *$ \\
\hline Durationc $^{c}$ & 3 & 4.1820 & 1.3940 & 2.548 \\
\hline Nc $x$ Light & 9 & 6.0129 & 0.6681 & 1.221 \\
\hline Nc x Day & 9 & 1.3153 & 0.1461 & 0.267 \\
\hline Light x Day & 9 & 5.1561 & 0.5729 & 1.047 \\
\hline Nc x Light $x$ Day & 27 & 9.6414 & 0.3571 & 0.653 \\
\hline Residuals & 192 & 105.0350 & 0.5471 & \\
\hline
\end{tabular}

\section{Results}

\subsection{Variations Chlorophyll A Content of P. Abbottae Responding To Environmental Variables}

Chlorophyll $a$ contents of the conchocelis of P. abbottae were significantly influenced by all three factors, including most of the interactions on chlorophyll $a$ content (Table 1).

Conchocelis cultures with no nutrients added generally 
had significantly lower pigment contents for longer culture duration (20-60 days), but not for 10-day culture. At high
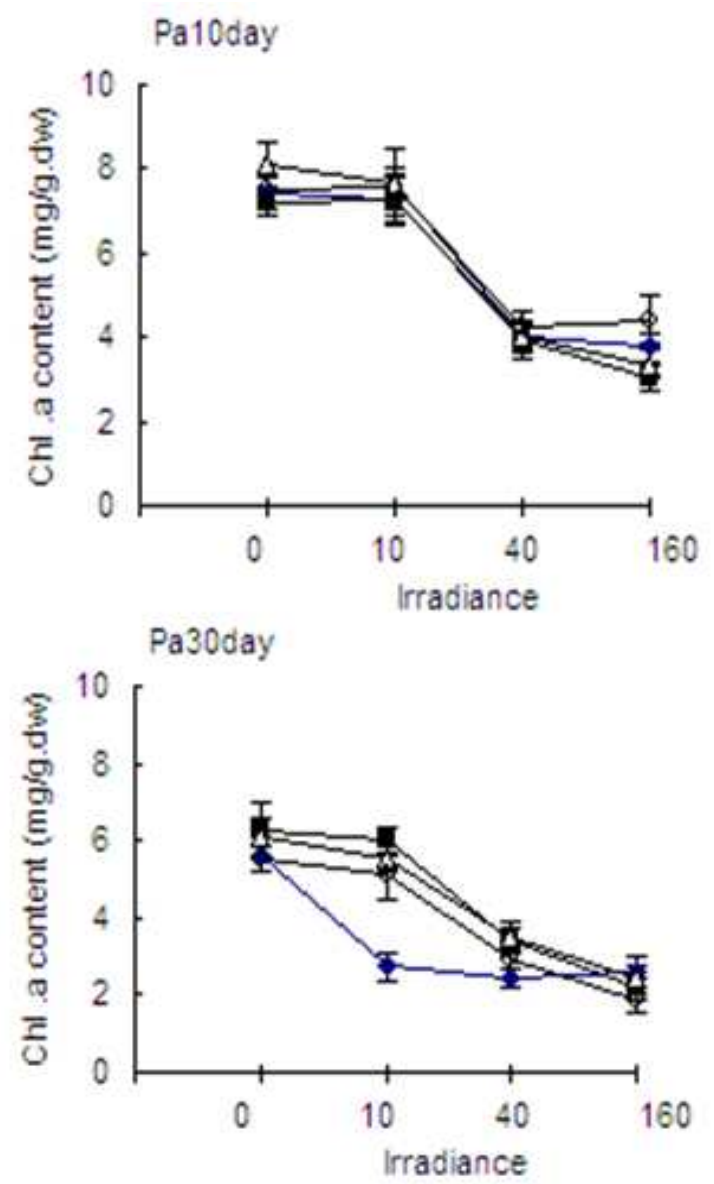

irradiances, cultures with no nutrients added had lowest pigment contents (Fig.1).
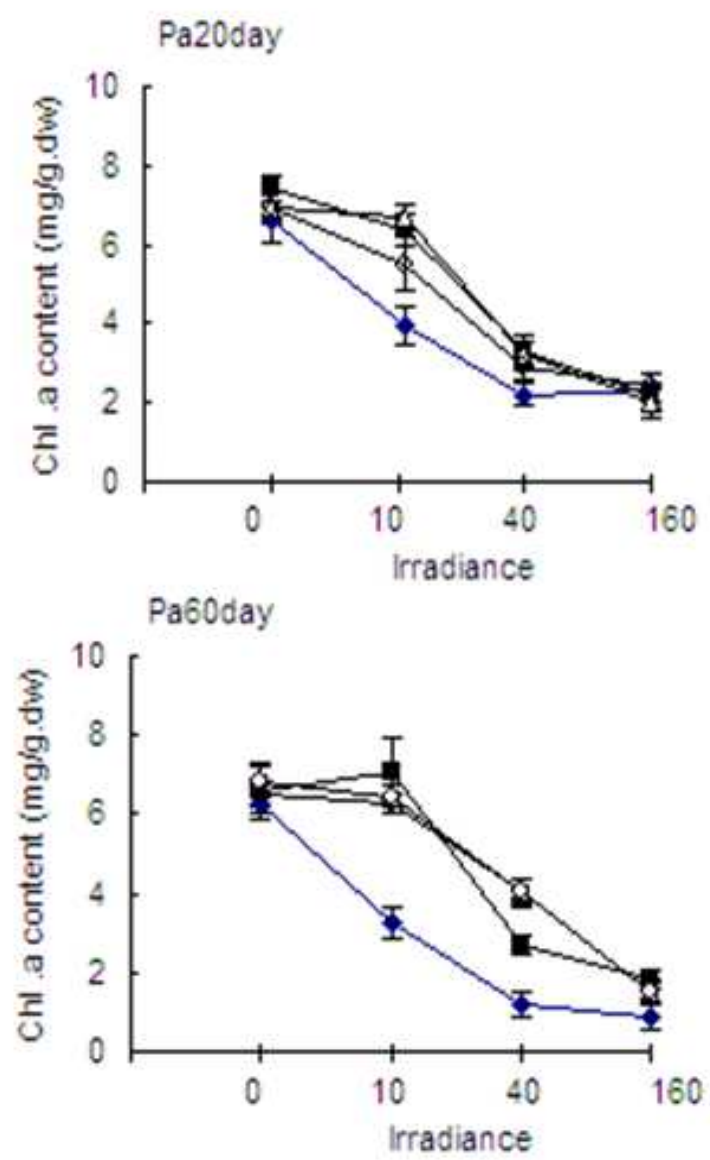

Fig 1. P. abbottae (Pa). Chlorophyll a content of the conchocelis as a function of irradiance, nutrient concentration ( $\bullet, 0 ; \boldsymbol{\nabla}, \mathrm{f} / 4 ; \Delta, \mathrm{f} / 2 ; \mathrm{O}, \mathrm{f})$ and culture duration. Error bars are \pm S.E

Chlorophyll $a$ contents of $P$. abbottae also varied with different light environments. Cultures in the darkness or at a low irradiance $\left(10 \mu \mathrm{mol}\right.$ photons $\left.\mathrm{m}^{-2} \mathrm{~s}^{-1}\right)$ had higher pigment contents. Irradiances of $40-160 \mu \mathrm{mol}$ photons $\mathrm{m}^{-2}$ $\mathrm{s}^{-1}$ resulted in a remarkable decline in pigment content. The favorable light environment for the production of pigments was a dark environment or a low irradiance which caused the highest content of chlorophyll $a$.

Pigment contents did not obviously decrease with culture duration of 10-60days, although there was a slight variation for a long duration of culture (Fig.1, Fig.5)

The mean maximal chlorophyll $a$ content $\left(8.2 \mathrm{mg} \mathrm{g.dw}^{-1}\right)$ was achieved at $0 \mu \mathrm{mol}$ photons $\mathrm{m}^{-2} \mathrm{~s}^{-1}, \mathrm{f} / 4-\mathrm{f} / 2$ nutrient concentration and 10-20day culture duration.

\subsection{Variations Chlorophyll A Content of P. Pseudolanceolata Responding To Environmental Variables}

Chlorophyll $a$ content was influenced by all three factors with the only one interaction (i.e interaction between irradiance and culture duration, Table1). Similarly, conchocelisl cultures with no nutrients added generally had low pigment contents for 10-60day culture duration. There was no a significant difference in chlorophyll $a$ content between different light environments, excepting significantly higher content occurring in the dark environment for 60day of culture (Fig.2)

Nutrients between $f / 4$ and $f$ concentrations did not significantly affect pigment contents of $P$. pseudolanceolata with the pooled mean of chlorophyll $a$ contents being 3.0-3.3 mg g.dw ${ }^{-1}$. However, cultures with no nutrient added had significantly lower pigment contents than those with nutrients added (Fig.2, Fig.5).

Basically, pigment contents of $P$. pseudolanceolata did not decline with culture duration. The highest chlorophyll $a$ was achieved at $0 \mu \mathrm{mol}$ photons $\mathrm{m}^{-2} \mathrm{~s}^{-1}$, f nutrient concentration and 20day culture duration for this species (Fig.2).

\subsection{Variations Chlorophyll A Content of P. Pseudolinearis Responding To Environmental Variables}

Pigment contents of the conchocelis of $P$. pseudolinearis were influenced by all three factors, including all 
interactions between these factors (Table 1).

Conchocelisl cultures with no nutrients added generally had lower pigment contents, particularly for longer culture duration
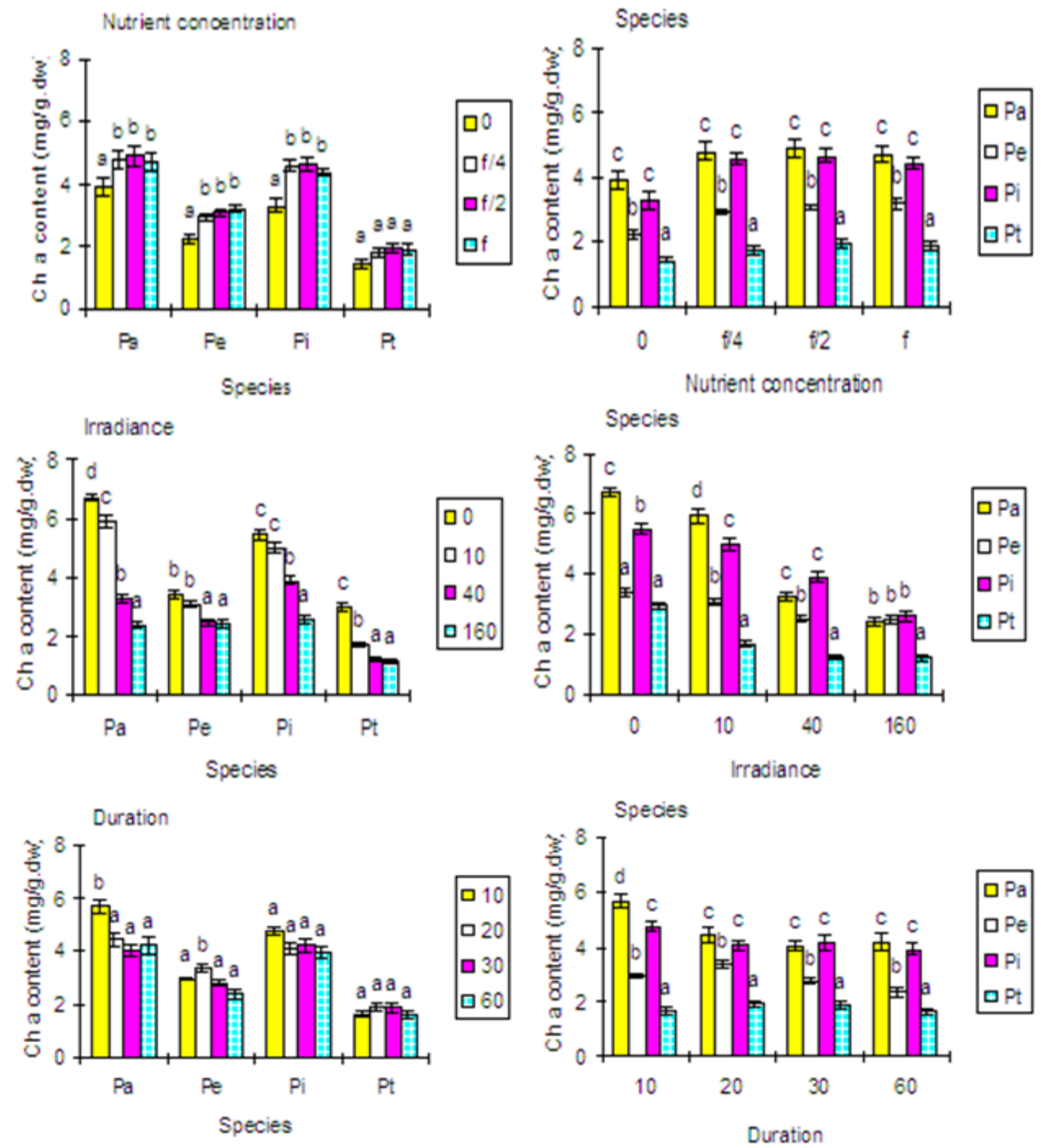

Fig 5. Comparison of pooled chlorophyll a (Chl a) content of Porphyra conchocelis for each parameter tested. Error bars are \pm S.E. Different letters above the bars indicate significant difference $(P<0.01)$ based on multiple comparisons using the Newman-Keuls test. Letter comparisons are relevant within a species (for left figures) and relevant between species (for right figures). Units of parameters tested are: irradiance ( $\mu$ mol photons $\mathrm{m}^{-2} \mathrm{~s}^{-1}$ ), nutrient concentration (expressed as the fraction) and culture duration (day).

Statistical test did not indicated that chlorophyll $a$ content of P. pseudolinearis decreased with culture duration, although there was a slight declining with a longer culture period (Fig. 5).

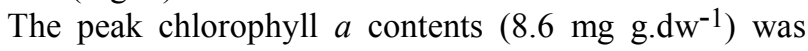

achieved at $0 \mu \mathrm{mol}$ photons $\mathrm{m}^{-2} \mathrm{~s}^{-1}, \mathrm{f} / 2$ nutrient concentration and 10day culture duration and $0 \mu \mathrm{mol}$ photons $\mathrm{m}^{-2} \mathrm{~s}^{-1}, \mathrm{f} / 2$ nutrient concentration and 10-day culture duration. 


\subsection{Variations Chlorophyll A Content of P. Torta Responding To Environmental Variables}

Among three factors, nutrient and light affected chlorophyll $a$ content of the conchocelis of P.torta but culture duration did not affect chlorophyll $a$ content of this species. There were no any interactions occurring among factors (Table 1).

Conchocelisl cultures with no nutrients added generally remained same pigment content as the cultures with nutrients added, except for cultures under dark environments. At higher irradiances, the cultures with no nutrients added generally had little variation in the pigment contents (Fig. 4)
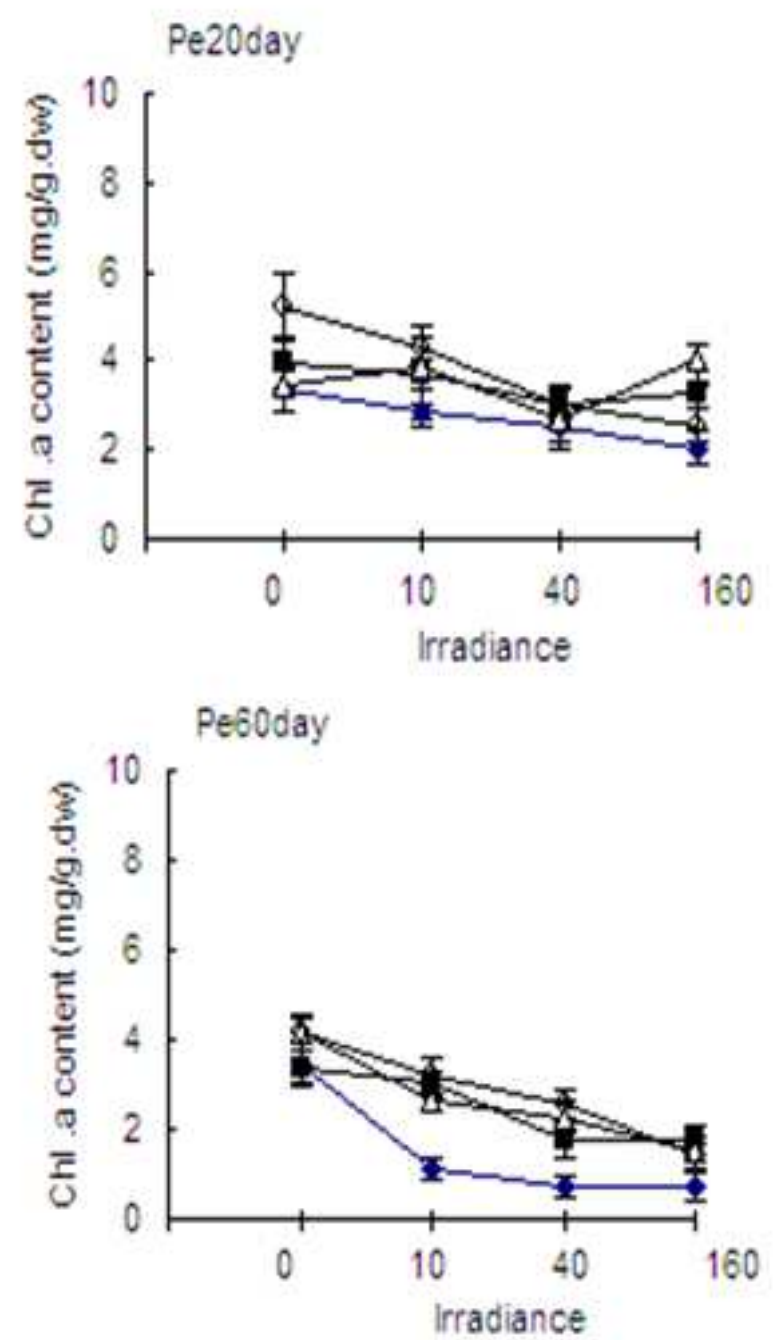

Fig 2. P. pseudolanceolata (Pe). Chlorophyll a content of the conchocelis as a function of irradiance, nutrient concentration ( $\bullet$, 0 ; $\mathbf{\square}, f / 4 ; \Delta, f / 2 ; 0, f)$ and culture duration. Error bars are \pm S.E.Pigment contents of P. pseudolinearis varied with different light environments. Cultures in the darkness or at the low irradiance with nutrients generally had higher pigment contents. At the higher irradiances (40-160 $\mu m o l$ photons $m-2 s-1)$, cultures with no nutrients added had especially low pigment contents (Fig.3).

Unlike the other three species, the conchocelis of $P$. torta produced more pigments under the dark environment than under the light environment. Cultures under the light environment had little variation in the pigment contents (Fig.4).

Similar to $P$. pseudolinearis, a decrease in pigment contents of $P$. torta with a longer culture was not statistically significant, although a slight declining tendency was observed (Fig.4, Fig.5).

The maximal pigment content was achieved at $0 \mu \mathrm{mol}$ photons $\mathrm{m}^{-2} \mathrm{~s}^{-1}$, f nutrient concentration and 30-day culture duration.

\subsection{The Effect Difference between Species Based On Pooled Pigment Content Data}

Comparison of pooled pigment contents of four species of Porphyra for each parameter tested (for comparison of effect difference between species) was shown in the right column of Fig.5. Results from those pooled data analyses showed that conchocelis of $\mathrm{Pa}$ and $\mathrm{Pi}$ contained significantly higher Chl. a contents than the other two species for the comparison of all levels of three factors 
(nutrient concentration, irradiance and culture duration). Pt had the lowest pigment contents for all levels of three factors (Fig.5).

Taking nutrient concentration into consideration, pooled
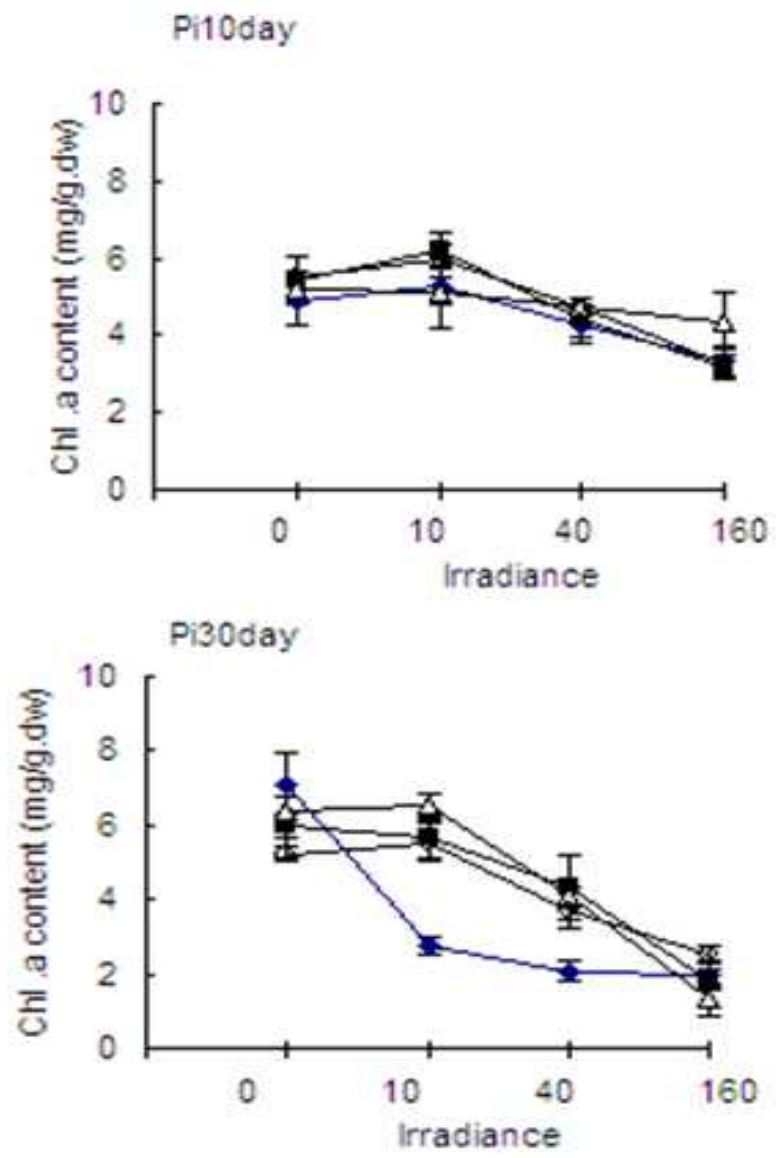

pigment contents showed the lowest Chl. a content occurred with no nutrient added for all four species of Porphyra, and much higher Chl. a content was observed with nutrients added excepting Pt.

Fig 3. P.pseudolinearis (Pi). Chlorophyll a content of the conchocelis as a function of irradiance, nutrient concentration ( $\bullet, 0 ; \mathbf{\square}, f / 4 ; 4, f / 2 ; O, f)$ and culture duration. Error bars are \pm S.E.

Pooled pigment contents also showed much higher Chl. a content appeared at complete darkness and the low irradiance for all four species of Porphyra(Fig.5). There was an obvious decrease in Chl. $a$ content at higher irradiances $\left(\geq 40 \mu \mathrm{mol}\right.$ photons $\left.\mathrm{m}^{-2} \mathrm{~s}^{-1}\right)$.

Pooled pigment contents indicated, basically there was no remarkable decline in Chl. $a$ content of four species of Porphyra for all culture duration (10-60 days) excepting 10 day of culture and other culture duration for $\mathrm{Pa}$.

The pooled pigment content data suggested that $\mathrm{Pa}$ and $\mathrm{Pi}$ could be potentially more suitable species for Porphyra cultivation based on their capacities to reserve more photosynthetic pigments responding to environmental variables.

Light had the most obvious influence on pigment content. For all four species, the higher Chl. $a$ content (3.6-8.1 $\mathrm{mg} / \mathrm{g} . \mathrm{dw}$ ) generally occurred at $0-10 \mu \mathrm{mol}$ photons $\mathrm{m}^{-2} \mathrm{~s}^{-1}$, $\mathrm{f} / 2-\mathrm{f}$ nutrient concentration and 10 day culture duration. Higher irradiances $\left(\geq 40 \mu \mathrm{mol}\right.$ photons $\left.\mathrm{m}^{-2} \mathrm{~s}^{-1}\right)$, low nutrients and longer culture duration generally caused a decline of photosynthetic pigment content.

\section{Discussions}

It was reported that the spectral absorbances of $\mathrm{P}$. abbottae gametophytes from Washington State increased in low light and high nutrient levels and P. abbottae blades grown under different conditions contained 4.7-7.2 $\mathrm{mg}$ of Chl. a $\mathrm{g} \mathrm{dw}-1$ if a conventional conversion coefficient 10 was used for the ratio of fresh and dry weight of red algae. Compared with our experimental results, it appeared that both sporophytic and gametophytic stages of P. abbottae have similar chlorophyll a content range [43].

From our results, pigment levels were found to vary inversely with the amount of available light, which was higher at the low irradiance and had a significant decline at the higher irradiance. This is an interesting and worth-discussed phenomenon, e.g., what are its implications and significances in physiological, ecological and biological aspects for Porphyra conchocelis? Here are 
some possible interpretations. In red algal cells, the photosynthetic pigments are associated closely with proteins in the thylakoid membranes of chloroplasts to form light-harvesting complexes. Occurrence of photosynthetic activity must rely upon pigment-protein complexes, which structurally are biological macro-molecules and needs some time for their synthesis in plant cells. Unlike sun plants or other plants which can, more or less, obtain regular light, cryptic Porphyra sporophytes have relatively very few
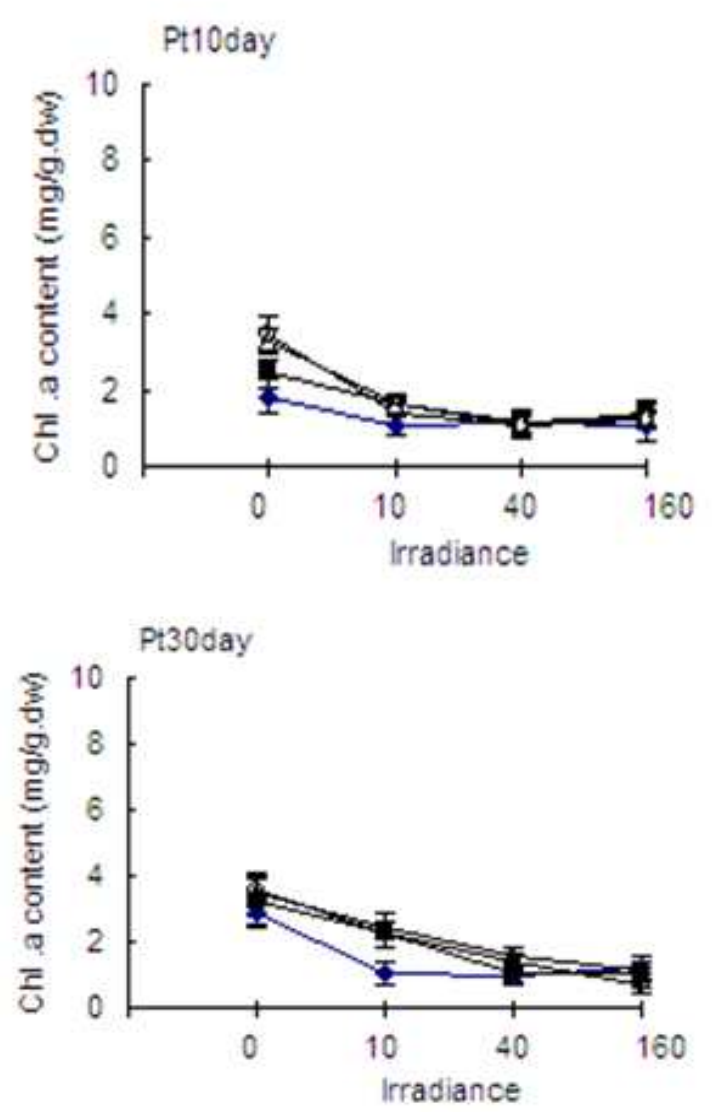

chances to access the light. Therefore, as an adaptation mechanism, one possible reason that they still maintain the higher content of photosynthetic pigments under the low light or complete darkness is in order to catch and utilize light, i.e. their photosynthetic pigments are ready for light harvesting at any time when light becomes available. Thus, these characteristics could likely be owned by the benthic red algae. This could be interpreted as increasing pigments to maximize numbers of the photons collected.
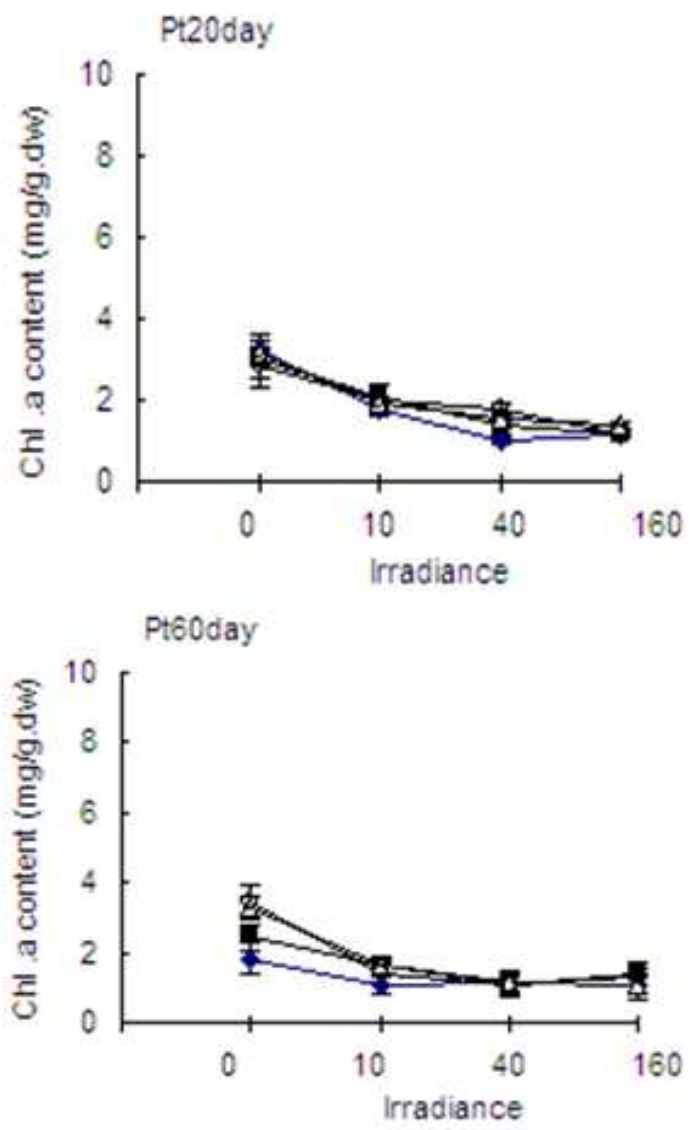

Fig 4. P. torta (Pt). Chlorophyll a content of the conchocelis as a function of irradiance, nutrient concentration ( $\bullet, 0 ; \boldsymbol{\square}, f / 4 ; 4, f / 2 ; O, f)$ and culture duration. Error bars are \pm S.E.

Because photosynthetic pigments are most essential for plants to perform photosynthetic process, variations of pigment contents likely determine the growth, development, physiological responses and the survival of plants [43-46]. Our experimental findings showed that photosynthetic pigments of the conchocelis for four Porphyra species are significantly influenced by environmental factors such as irradiance, nutrient concentration and culture duration, including some interactions among these factors. Therefore, pigment contents of the conchocelis appear to be sensitive to the environmental change and could be used to indicate physiological responses of sporophytic stage of Porphyra.

Overall, the conchocelis of all species of Porphyra tested produced and maintained higher content of photosynthetic pigments in the dark environment or at a low irradiance (10 $\mu$ mol photons $\mathrm{m}^{-2} \mathrm{~s}^{-1}$ ). Such a unique physiological trait, which derived likely from the historical acclimation and adaptation to environments and the process of natural selection, could possess particularly important biological implication for them to survive and persist in the habitats with very limited light source and could also partly explain the cause why these indigenous Porphyra species could exist and persist in high-altitude habitats (like in Alaska) with very limited light available. Variation and magnitude of pigment contents of the conchocelis vary considerably from species to species in response to varying environments. Our research findings showed that Porphyra conchocelis had the peculiar adaptability to the dark environment or a low irradiance.

Many studies indicated that nutrients, especially nitrogen could affect both growth and development of marine algae [47-55]. Our experimental results also indicated that nutrients are very important for the sporophytic stage of Porphyra. Under culture conditions, conchocelis grown in 
the media with nutrients added usually had much higher contents of photosynthetic pigments and evidently exhibited healthy color, in contrast to cultures with no nutrients added that had very little amount of photosynthetic pigments and turned into bleached color. Nitrogen source and supply in coastal waters generally take place with immense seasonal fluctuations and are related to the seasonal occurrence, which could result in the variations of growth and abundance of marine algae [43, 47, 55]. In natural habitats, since Porphyra sporophytes occur mainly during the period of summer season for the most of species, without doubt, their occurrences during this season would encounter the limiting nitrogen availability. For instance, in Alaska, a drastic decline of nutrient concentration usually occurs during the late spring and summer as the result of frequent phytoplanton blooms. Hence, shortage of nutrient supply during this period would exert a potentially negative effect on the growth, development and survival of natural populations of Porphyra sporophytes.

Sufficient nutrient surpply is necessary to promote higher pigment content for Porphyra conchocelis. However, different species exhibited differences in nutrient requirements. For example, higher nutrient concentration (f concentration) might be needed for $P$. pseudolanceolata. For the other three species, intermediate nutrient concentrations (f/4-f/2) were basically sufficient for high pigment contents. Culture duration also should be taken into consideration for Porphyra conchocelis to produce more pigments. $P$. abbottae tended to synthesize significantly less photosynthetic pigments with prolonged culture duration, in contrast to the other three species having a relative constancy in pigment production throughout the entire period of culture.

Our findings have indicated the environmental variables could exert significant influences on chlorophyll a content for three factors tested. Particularly the presence of interactions could have important implications for the interpretation of the variations of chlorophyll a content (Table1). It is observed that interactions occurred in almost all environmental variables for $\mathrm{Pa}$ and $\mathrm{Pi}$ species, this implied that more flexible variations of chlorophyll a content existed responding to environmental variables for these two species. Therefore it is more possible to produce the conchocelis cultures with healthy and higher chlorophyll a content for these two species through modifying those environmental variables. In contrast, there is no interaction occurring while simultaneous existence of environmental variables tested for $\mathrm{Pt}$ species. This suggested that $\mathrm{Pt}$ could maintain stable chlorophyll a content in spite of the changes in environmental variables. This species appeared there is less potential prospect in Porphyra culture for another reason of its lowest chlorophyll a content.

Since plants rely on various photosynthetic pigments to perform photosynthetic process, photosynthetic pigments play a crucial role in sustaining all life activities in plant cells. Conchocelis is critical to successful mariculture of Porphyra. Possibility of conchospore maturation and release, to a great extent, rests on whether or not the best cultures of the conchocelis are grown. On the other hand, the importance of marine algae as sources of functional ingredients has been well recognized due to their valuable health beneficial effects. Various bioactives isolated from marine algae have also attracted increasing attention in the fields of food, cosmetic and pharmacology [56-65]. The optimal culture conditions at which the highest production of photosynthetic pigments occurred could not only provide high quality and healthy conchocelis for successful maricultivation of these indigenous Porphyra species but also other potentially high value accessory products such as phycoerythrin, phycocyanin and carotenoids which possess potential active biological functions serving as antioxidants for exploiting and utilizing phycological resources[66-69].

\section{Acknowledgements}

The work reported here was supported by Saltonstall-Kennedy Funding (NA76FD0035) administered through NOAA, U.S. Department of Commerce and in part by special research project funding of China National marine public service industry (Grant No 201005020-2).We thank S. Lindstrom for assistance with this research including algal identifications. We also thank C. Good and S. Hall for their assistance in the laboratory. The manuscript was improved greatly by the valuable comments and editing by the anonymous reviewers.

\section{References}

[1] Lindstrom. S. C. \& K. M. Cole, 1992. A revision of the species of Porphyra (Rhodophyta: Bangiales) occurring in British Columbia and adjacent waters. Can. J. Bot. 70: 2066-2075.

[2] Stekoll, M. S., 1998. The seaweed resources of Alaska. In M. Ohno \& A. T. Critchley (eds), Seaweed Resources of the World. Japan International Cooperation Agency, Tokyo: 258-265.

[3] FAO (Food and Agriculture Organization of the United Nations). 2010. Global Production Statistics 1950-2006. Available at: http:/ www.fao.org/fishery/statistics/global-aquaculture-productio $\mathrm{n} /$ query/en (last accessed 9 December 2010).

[4] Buchholz, C.M., G. Krause, \& B.H. Buck. 2012. Seaweed and Man. Seaweed Biology Ecological Studies. 219: 471-493.

[5] Okai, Y., Hiqashi Okai, K., Yano, Y., \& Otani, S. 1996. Identification of antimutagenic substances in an extract of edible red alga, Porphyra tenera (Asadusa-nori). Cancer Letters. 100: 235-240.

[6] Pereira, R., C. Yarish, \& A. T. Critchley. 2013. Seaweed Aquaculture for Human Foods in Land-Based and IMTA Systems. Sustainable Food Production. 1405-1424. 
[7] Rulong Lin \& Michael S. Stekoll. 2011. Phycobilin content of the conchocelis phase of Alaskan Porphyra (Bangiales, Rhodophyta) species: Responses to environmental variables. J. Phycol. 47: 208-214.

[8] Yabuta, Y., Fujimura, H., Kwak, C. S., Enomoto, T., \& Watanabe, F. 2010. Antioxidant activity of the phycoerythrobilin compound formed from a dried Korean purple laver (Porphyra sp.) during in vitro digestion. Food Science and Technology Research. 16: 347-352.

[9] Yasuji Okai, Kiyoka Higashi-Okai, Yoshihisa Yano, Shuzo Otani. 1996. Identification of antimutagenic substances in an extract of edible red alga, Porphyra tenera (Asadusa-nori) Cancer Letters.100(1-2): 235-240.

[10] Akpan, E. B. \& Farrow, G. E. 1984. Shell-boring algae on the Scottish continental shelf: identification, distribution, bathymetriczonation. Trans. R. Soc. Edinb. 75:1-12.

[11] Farrow, G. E. \& Clokie, J. 1979. Molluscan grazing of sublittoral algal-bored shells and the production of carbonate mudin the Firth of Clyde, Scotland. Trans. R. Soc. Edinb. 70:139-48.

[12] Gantt, E., G. M. Berg, D. Bhattacharya et al. 2010 Porphyra: Complex life histories in a harsh environment: $P$. umbilicalis, an intertidal red alga for genomic analysis. Red Algae in the Genomic Age, Cellular Origin, Life in Extreme Habitats and Astrobiology. 13: 129-148.

[13] Martinez, E. 1990. The conchocelis-phase of Porphyra (Rhodophyta) in the intertidal of San Juan Island, Washington, USA. Phycologia.29:391-5.

[14] Nielsen, R. 1987. Marine algae within calcareous shells from New Zealand. N. Z. J. Bot. 25:425-38.

[15] He, P. \& C. Yarish.2006. The developmental regulation of mass cultures of free-living conchocelis for commercial net seeding of Porphyra leucosticta from Northeast AmericaAquaculture. 257:373-381.

[16] Stekoll, M. S., Lin, R. \& Lindstrom, S. C. 1999. Porphyra cultivation in Alaska: conchocelis growth of three indigenous species. Hydrobiologia 398/399:291-7.

[17] Amano, H. \& Noda, H. 1978. Photosynthetic pigments of five kinds of laver, "nori." Bull. Jpn. Soc. Sci. Fish. 44:911-6.

[18] Figueroa, F. L., Aguilera, J. \& Niell, F. X. 1995. Red and blue light regulation of growth and photosynthetic metabolism in Porphyra umbilicalis (Bangiales, Rhodophyta). Eur. J. Phycol. 30: 11-8.

[19] Fujita, Y. \& Migita, S. 1984. Photosynthetic pigments of the different color types of Porphyra yezoensis Ueda and $P$ tenera Kjellman. Bull. Fac. Fish. 56:7-13.

[20] S. Abe, A. Kurashima, Y. Yokohama and J. Tanaka. 2001. The cellular ability of desiccation tolerance in Japanese intertidal seaweeds. Bot. Mar. 44:125-131

[21] Conway, E. \& Cole, K. 1977. Studies in the Bangiaceae: structure and reproduction of the conchocelis of Porphyra and Bangia in culture (Bangiales, Rhodophyceae). Phycologia 16:205-16.

[22] Chang, S. D., Chin, P. \& Park, K. Y. 1983. Effects of temperature, salinity and clay on the rate of photosynthesis of laver, Porphyra yezoensis. Bull. Korean Fish. Soc. $16: 335-40$

[23] Herbert, S. K. 1984. Acclimation to light intensity in a winter and a summer species of Porphyra. J. Phycol. 20 (Suppl. 1):4.

[24] Gao, K. \& Aruga, Y. 1987. Preliminary studies on the photosynthesis and respiration of Porphyra yezoensis under emersed conditions. J. Tokyo Univ. Fish. 47:51-65.

[25] Gao, S. \& Zhao, H. 1988. Studies on acid tolerance of Porphyra and Ulva. Effects of different $\mathrm{pH}$ on the photosynthesis and cellular structure of Porphyra yezoensis and Ulva pertusa. Oceanol. Limnol. Sin. 19:87-92.

[26] Gao, K., Aruga, Y., Asada, K., Ishihara, T. \& Kiyohara, M. 1991. Enhanced growth of the red alga Porphyra yezoensis Ueda in high $\mathrm{CO} 2$ concentrations. J. Appl. Phycol. $3: 355-62$.

[27] Kapraun, D. F. \& Lemus, A. J. 1987. Field and culture studies of Porphyra spiralis var. amplifolia Olivera Filho et Coll (Bangiales,Rhodophyta) from Isla de Margarita, Venezuela. Bot. Mar.30:483-90.

[28] Lipkin, Y., Beer, S. \& Eshel, A. 1993. The ability of Porphyra linearis (Rhodophyta) to tolerate prolonged period of desiccation. Bot. Mar. 36:517-23.

[29] Niwa, K. et al. 2005. Morphological and molecular analysis of the endangered species Porphyra tenera (Bangiales, Rhodophyta). J. Phycol., 41:294-304.

[30] Pereira, R., Sousa-Pinto, I. \& Yarish, C. 2004. Field and culture studies of the life history of Porphyra dioica (Bangiales, Rhodophyta) from Portugal. Phycologia. 43:756-67.

[31] Wiencke, C. \& Clayton, M. N. 1998. The life history of Porphyra endiviifolium from the South Shetland Islands, Antarctica. Polar Biol. 19:257-63.

[32] Tang, X., Jiang, H., Fei, X. \& Yarish, C. 2004. New life cycles of Porphyra katadae var. hemiphylla in culture. $J$. Appl. Phycol. 16:505-11.

[33] Holmes, M. J. \& Brodie, J. 2005. Phenology and the life history in culture of Porphyra leucosticta (Bangiales, Rhodophyta) from Britain. Bot. Mar. 48:218-30.

[34] Monotilla, W. \& M.. Notoya. 2004. Morphological and physiological responses of Porphyra suborbiculata Kjellman (Bangiales, Rhodophyta) blades from five localities. Bot. Mar., 47: 323-334.

[35] Christopher D. Neefus, Arthur C. Mathieson1, Troy L. Bray1, Charles Yarish. 2008. The distribution, morphology, and ecology of three introduced Asiatic species of Porphyra (Bangiales, Rhodophyta) in the Northwestern Atlantic. $J$. Phycol., 44(6): 1399-1414.

[36] Priya Sampath-Wiley, Christopher D. Neefus and Leland S. Jahnke. 2008. Seasonal effects of sun exposure and emersion on intertidal seaweed physiology: fluctuations in antioxidant contents, photosynthetic pigments and photosynthetic efficiency in the red alga Porphyra umbilicalis Kützing (Rhodophyta, Bangiales). J. Exp. Mar. Biol. Ecol., 361(2):83-91.

[37] Korbee, N., F. L. Figueroa \& J. Aguilera. 2005. Effect of 
light quality on the accumulation of photosynthetic pigments, proteins and mycosporine-like amino acids in the red alga Porphyra leucosticta (Bangiales, Rhodophyta). Journal of Photochemistry and Photobiology B: Biology, 80(2): 71-78.

[38] Kursar, T.A., J.P. van der Meer \& R.S. Alberte. 1983. Light-harvesting system of the red alga Gracilaria tikvahiae. Plant Physiol. (Bethesda). 73:353-360.

[39] McLachlan, J. 1973. Growth media-marine. In Stein, J. R. [Ed.]Handbook of Phycological Methods. Culture Methods and Growth Measurements. Cambridge University Press, Cambridge, UK,pp. 25-51.

[40] O'hEocha,C. 1971. Pigments of the Red Algae. In Barnes, H. [Ed.] Oceanogr. Mar. Biol. Ann.Rev. George Allen and Unwin Ltd., London. 9: pp. 61-82.

[41] Statistical Sciences Inc. 2000. S-Plus for Windows Version 4.5. Seattle, Washington.

[42] Zar,J.H. 2010. Biostatistical analysis the fifth edition, Prentice-Hall, Upper Saddle River, NJ, USA. 960pp.

[43] Hannach, G. 1989. Spectral light absorption by intact blades of Porphyra abbottae (Rhodophyta): effects of environmental factors in culture. J. Phycol. 25:522-529.

[44] Fortes, M.D. \& K. Luning. 1980. Growth rates of North Sea macroalgae in relation to temperature, irradiance and photoperiod. Helgolander Meeresuntersuchungen. 34: $15-29$.

[45] Waaland, J.R., S.D. Waaland \& G. Bates. 1974. Chloroplast structure and pigment composition in the red alga Griffithsia pacifica: regulation by light intensity. J. Phycol. 10:193-199.

[46] Zavodnik, N. 1987. Seasonal variations in the rate of photosynthetic activity and chemical composition of the littoral seaweeds Ulva rigida and Porphyra leucostcta. Bot. Mar. 30 (1): 71-82.

[47] Grobe, C.W., C. Yarish \& I.R. Davison. 1998. Nitrogen: a critical requirement for Porphyra aquaculture. World Aquaculture. 6: 34-35.

[48] Kim, J.K., Kraemer G.P., Neefus C.D., Chung I.K. and Yarish C. 2007. The effects of temperature and ammonium on growth, pigment production and nitrogen uptake in four species of Porphyra native to the coast of New England. $J$. Appl. Phycol., 19:431-440.

[49] Jang K. Kim, George P. Kraemer, Charles Yarish. 2009. Comparison of growth and nitrate uptake by New England Porphyra species from different tidal elevations in relation to desiccation. Phycol. Res., 57(2):152-157.

[50] N. Korbee, P. Huovinen, F. L. Figueroa, J. Aguilera and U. Karsten. 2005. Availability of ammonium influences photosynthesis and the accumulation of mycosporine-like amino acids in two Porphyra species (Bangiales, Rhodophyta).Mar. Biol., 146:645-654.

[51] Korbee, N., F. L. Figueroa \& J. Aguilera. 2010. Effect of nutrient supply on photosynthesis and pigmentation to short-term stress (UV radiation) in Gracilaria conferta (Rhodophyta). Marine Pollution Bulletin. 60(10): $1768-1778$

[52] Lapointe, B.E. \& J. Ryther. 1979. The effects of nitrogen and seawater flow rate on the growth and biochemical composition of Gracilaria foliffera var. angustissima in mass outdoor cultures. Bot. Mar. 22:529-537.

[53] Meiqin, C., Z. Baofu \& W. Jicheng. 1979. The influence of different nitrogenous fertilizers on the growth and development of the conchocelis of Porphyra yezoensis. Oceanol. Limnol. Sin. 10 (1): 45.

[54] Rui Pereiraac, George Kraemerd, Charles Yarishc \& Isabel Sousa-Pintoab. 2008. Nitrogen uptake by gametophytes of Porphyra dioica (Bangiales, Rhodophyta) under controlled-culture conditions. Eur. J. Phycol., 43(1):107-118.

[55] Wheeler, P.A. \& W.J. North. 1980. Effect of nitrogen supply on nitrogen content and growth rate of juvenile Macrocystis pyrifera (Phaeophyta) sporophytes. J. Phycol. 16: 577-582

[56] Mario, G., Ferruzzi, J. Blakeslee. Digestion, absorption, and cancer preventative activity of dietary chlorophyll derivatives. Nutrition Research, 27(1): 1-12.

[57] Hafting, J.T., Alan T. Critchley, M. Lynn Cornish et al., 2012. On-land cultivation of functional seaweed products for human usage. Journal of Applied Phycology.24(3): 385-392.

[58] Rindi, F., A. Soler-Vila \& M. D. Guiry. 2012. Taxonomy of Marine Macroalgae Used as Sources of Bioactive Compounds. Marine Bioactive Compounds. 1-53.

[59] Holdt, S. L., \& S. Kraan. 2011. Bioactive compounds in seaweed: functional food applications and legislation. Journal of Applied Phycology.23(3): 543-597.

[60] Pangestutia, R. \& S. K. Kim. 2011. Biological activities and health benefit effects of natural pigments derived from marine algae. J. Functional Foods. (3): 255-266.

[61] Lanfer-Marquez, U. M., R. Barros \& P. Sinnecker. 2005. Antioxidant activity of chlorophylls and their derivatives. Food Research International. 38: 885-891.

[62] Maeda, H., Hosokawa, M., Sashima, T., \& Miyashita, K. 2008. Antiobesity effect of fucoxanthin from edible seaweeds and its multibiological functions. Functional food and health. 376-388.

[63] Bohn, T. 2008. Bioavailability of non-provitamin A carotenoids. Current Nutrition and Food Science. 4: $240-258$.

[64] Cho, M. L., Lee, H. S., Kang, I. J., Won, M. H., \& You, S. G. 2011. Antioxidant properties of extract and fractions from Enteromorpha prolifera, a type of green seaweed. Food Chemistry.127: 999-1006.

[65] Cornish, M., \& Garbary, D. 2010. Antioxidants from macroalgae: Potential applications in human health and nutrition. Algae. 25: 155-171.

[66] Ferruzzi, M. G., \& Blakeslee, J. 2007. Digestion, absorption, and cancer preventative activity of dietary chlorophyll derivatives. Nutrition Research. 27: 1-12.

[67] Sachindra, N., Sato, E., Maeda, H., Hosokawa, M., Niwano, Y., Kohno, M., et al. 2007. Radical scavenging and singlet oxygen quenching activity of marine carotenoid fucoxanthin and its metabolites. Journal of Agricultural and Food Chemistry, 55:8516-8522.

[68] Sekar, S., \& Chandramohan, M. 2008. Phycobiliproteins as 
a commodity: Trends in applied research, patents and commercialization. Journal of Applied Phycology, 20: 113-136.
[69] Shahidi, F. 2008. Bioactives from marine resources. In ACS symposium series (pp. 24-34). ACS Publications. 